\title{
Violence and depression among pregnant women in Egypt
}

\author{
Hanan M. Ghoneim, Mohamed Elprince* (10, Tamer Yehia M. Ali, Waleed F. Gharieb and Amal A. Ahmed
}

\begin{abstract}
Background: Depression is a serious mental health disorder that might affect women in the childbearing period. Incidences increase during pregnancy as well as after delivery. Its association with intimate partner violence (defined as physical, sexual, or psychological harm by a current or former partner) has been reported in many countries. Data about this sensitive issue are lacking in Egypt. The aim of the study was to determine the relation between intimate partner violence and depression during pregnancy.

Methods: This was a case control study conducted at the outpatient clinics in Suez Canal University hospital, from January 2019 to March 2020. The study included two groups, the study group included women exposed to violence during the current pregnancy and a control one included women with no history of violence. Both groups were recruited according to the predetermined inclusion criteria (women aged 18-45 years, continuous marital relationship, no history of depression in current or previous pregnancies, and singleton pregnancy). Women were asked to complete the Arabic validated NorVold Domestic Abuse Questionnaire (measuring four types of abuse: emotional, physical, sexual, and violence in the health care system, the last one being excluded). Depression was evaluated using the Arabic validated form of the Edinburgh Postnatal Depression Scale (comprises 10 questions that represent patients' feelings in the last 7 days). The main outcome measure was to assess the association between intimate partner violence and depression.

Results: We recruited 158 women in each group. Both groups were matched in their demographic characters. Although emotional violence was reported prominently among women exposed to IPV 87.9\% (139/158), it was not significantly reported in depressed women ( $P$ value 0.084$)$. Physical and sexual violence were significantly reported among depressed women ( $P$ value 0.022 and 0.001 , respectively). There was a significant difference between women exposed to violence and those who were not exposed to violence in the total depression scores (13.63 \pm 5.47 and $10.65 \pm 5.44$, respectively with a $p$ value $<0.001$ ). Emotional ( $p$ value $<0.001$ ) and sexual violence (mild and severe with $p$ value of 0.026 and 0.002 respectively) had significant roles as risk factors for depression during pregnancy in single regression and after control of other confounders.
\end{abstract}

Conclusion: There was a strong association between intimate partner violence and depression during pregnancy. Keywords: Antepartum, Depression, Violence

\footnotetext{
* Correspondence: prince.ma939@yahoo.com

Department of Obstetrics and Gynecology, Faculty of Medicine, Suez Canal University, Round Road, Ismailia, Egypt
}

(c) The Author(s). 2021 Open Access This article is licensed under a Creative Commons Attribution 4.0 International License, which permits use, sharing, adaptation, distribution and reproduction in any medium or format, as long as you give appropriate credit to the original author(s) and the source, provide a link to the Creative Commons licence, and indicate if changes were made. The images or other third party material in this article are included in the article's Creative Commons licence, unless indicated otherwise in a credit line to the material. If material is not included in the article's Creative Commons licence and your intended use is not permitted by statutory regulation or exceeds the permitted use, you will need to obtain permission directly from the copyright holder. To view a copy of this licence, visit http://creativecommons.org/licenses/by/4.0/. The Creative Commons Public Domain Dedication waiver (http://creativecommons.org/publicdomain/zero/1.0/) applies to the data made available in this article, unless otherwise stated in a credit line to the data. 


\section{Background}

Depression, anxiety, and somatoform disorders affect women during pregnancy [1] with depression the most serious one [2]. It has a wide range of risk factors including poverty, illiteracy, unemployment, social deprivation, and intimate partner violence (IPV) $[3,4]$. IPV has numerous unwanted effects on physical and mental health [5]. According to WHO estimates, about one- third of women are exposed to one form of violence (physical or sexual) during their lifetime, while emotional violence predominated significantly [5]. IPV is the most common type of violence practiced against women worldwide [6]. For example; $46 \%$ of Ugandan women, $60 \%$ of Tanzanian women, $42 \%$ of Kenyan women, and $40 \%$ of Zambian women reported physical abuse [7]. However; its global estimates are not accurate because of the stigma and shame associated with IPV. Also, disclosure is low and taboos about revealing such family problems exist among certain cultural groups [8].

Recent studies demonstrated the relation between IPV and postpartum depression (PPD) [9], while depression is the most common psychiatric disorder during pregnancy [10]. It has a significant cargo during pregnancy, with higher prevalence than PPD [11]. Besides, it is considered a major risk factor for PPD, with about $41.5 \%$ of PPD being developed during pregnancy [12].

Accordingly, there is an urgent need to gather evidence-based information to solve the problem appropriately. Although many studies exist, the impact of violence on women's health during pregnancy remains an area where robust evidence is lacking. So, there is a need to disclose the association between IPV and women's health with special attention to mental health [7]. There are no studies evaluating the relation between IPV and depression during pregnancy, especially in Egypt. Early detection of depression, would lead to early intervention and the avoidance of disease progression [13]. The aim of this study was to determine the relationship between different forms of violence and depression during pregnancy among Egyptian women.

\section{Methods}

This was a case control study conducted in the outpatient clinics in Suez Canal University hospital, after approval of our research ethics committee. The study started from January 2019 to March 2020. We recruited women from the same general population attending for routine antenatal care. Women were invited consecutively every day. The aim of the study was explained for eligible participants. Women accepting to participate in the study were interviewed after they had received their care. At the end of the consultation, the participant was transferred to a private room to fill in the questionnaires.
Three hundred- fifty one women were eligible for the study. Twenty three women and twelve women refused to participate in the study and control groups respectively. This resulted in a total of 158 women in each group. We allocated women into two groups. The study group included women exposed to IPV during the current pregnancy and a control one included women with no history of IPV. Women were recruited according to the following inclusion criteria: a) women aged [18-]45 years, b) continuous marital relationship, c) no history of depression in previous or current pregnancy, d) singleton pregnancy, and e) gestational age in the second and third trimesters. Women who refused to participate in our research were excluded.

Patients were evaluated regarding their demographic parameters. These data were selected after literature review to determine possible factors contributing to maternal exposure to IPV $[14,15]$. These included age, level of education (illiterate, middle, and high), occupation (housewife, worker, and employee), parity, residency (urban or rural areas), and duration of marriage. Partners' data included age, level of education, and occupation. The socioeconomic level was determined according to the scale developed by El- Gilany et al. the scale included 7 domains with a total score of 84 . The socioeconomic level was classified as very low, low, middle, and high levels depending on the quartiles of the score calculated [16]. Women were asked to complete the Arabic validated NorVold Domestic Abuse Questionnaire (NORAQ). The NORAQ measures four types of abuse: emotional, physical, sexual, and violence in the health care system, the last one being excluded. The NORAQArabic version evaluated measurements of the three kinds of lifetime abuse - emotional (12 items), physical (11 items), and sexual abuse (12 items). The content of the questions ranged from mild to severe lifetime abuse. Women who reported more than one degree of a specific kind of abuse were categorized according to the most severe abusive act. Emotional, physical, and sexual abuses were defined by an affirmative answer to one or several of the three or four questions about each kind of violence in NORAQ [17].

Depression was evaluated using the Arabic validated form of the Edinburgh Postnatal Depression Scale (EPDS). The scale comprises 10 questions that represent patients' feelings in the last 7 days. Each question has multiple choices for answering it. Questions 1, 2, and 4 are scored $0,1,2$, or 3 with the top choice scored as 0 while the last one as 3. Questions 3, 5-10 are reverse scored with the top choice scored as 3 while the last one as 0 . The maximum score is 30 . Scores were interpreted as follows: a score less than 8 as depression was not likely, a score of 9-11 as depression was possible, a score of $12-13$ as fairly high possibility of depression, and a 
score $\geq 14$ as possible depression (positive screen). A positive score for question 10 meant suicidality risk. Each situation was dealt with according to the recommendations of the reproductive health program $[18,19]$.

Data collection was done by one of the study researchers, who had the interviews with each patient. An informed written consent was obtained from each participant before completing the questionnaire. The questionnaires were self- administered, anonymous, and without address, to ensure confidentiality. The available researcher provided help and clarification for patients when needed (also for illiterate patients). The average time for filling the questionnaire was $20-25 \mathrm{~min}$.

\section{Statistical analysis}

Data were statistically described in terms of mean and standard deviation, frequencies (number of cases) and percentages when appropriate. $P$ values less than 0.05 were considered statistically significant. All statistical calculations were done using computer program SPSS (Statistical Package for the Social Science; SPSS Inc.
2013, Chicago, IL, USA) release 22 for Microsoft Windows. For comparing proportions between groups, Chi squared or Fisher's Exact tests were used. Mann- Whitney $\mathrm{U}$ test was used for comparison of quantitative continuous non- parametric variables. For the construction of logistic regression models for the prediction of antenatal depression the dependent variable was the presence or absence of depression. This was put against all of the variables that it depended upon; hence, there were multiple simple logistic models each with a significant factor. These significant factors were put in a model and factors were removed one by one to produce a best-fit multiple logistic model. A $p$-value $\leq 0.05$ was considered statistically significant.

\section{Results}

Three hundred- fifty one women were eligible for the study. Twenty three women and twelve women refused to participate in the study and control groups respectively. This resulted in a total of 158 women in each group. Both groups were matched in their demographic characters (Table 1).

Table 1 Descriptive statistics of the sociodemographic variables of the study groups

\begin{tabular}{|c|c|c|c|c|}
\hline \multicolumn{2}{|l|}{ Group } & \multirow{2}{*}{$\begin{array}{l}\text { No IPV (158) } \\
28.58 \pm 5.61\end{array}$} & \multirow{2}{*}{$\begin{array}{l}\text { IPV (158) } \\
28.34 \pm 5.17\end{array}$} & \multirow{2}{*}{$\frac{p \text {-value }}{0.799}$} \\
\hline Wife's age (years) (mean $\pm s d$ ) & & & & \\
\hline \multirow[t]{3}{*}{ Wife's education N (\%) } & Illiterate & $42(26.58 \%)$ & $47(29.75 \%)$ & \multirow[t]{3}{*}{0.822} \\
\hline & Middle & $75(47.47 \%)$ & $72(45.57 \%)$ & \\
\hline & High & $41(25.95 \%)$ & $39(24.68 \%)$ & \\
\hline \multirow[t]{3}{*}{ Wife's occupation N (\%) } & Housewife & $113(71.52 \%)$ & $103(65.19 \%)$ & \multirow[t]{3}{*}{0.407} \\
\hline & Worker & $10(6.33 \%)$ & 15 (9.49\%) & \\
\hline & Employee & $35(22.15 \%)$ & $40(25.32 \%)$ & \\
\hline Husband's age (years) (mean \pm & & $32.54 \pm 5.81$ & $32.82 \pm 5.28$ & 0.705 \\
\hline \multirow[t]{3}{*}{ Husband's education N (\%) } & Illiterate & $48(30.38 \%)$ & $51(32.28 \%)$ & \multirow[t]{3}{*}{0.347} \\
\hline & Middle & $66(41.77 \%)$ & $74(46.84 \%)$ & \\
\hline & High & $44(27.85 \%)$ & $33(20.89 \%)$ & \\
\hline \multirow[t]{3}{*}{ Husband's occupation N (\%) } & Unemployed & $33(20.89 \%)$ & $26(16.46 \%)$ & \multirow[t]{3}{*}{0.417} \\
\hline & Worker & $50(31.65 \%)$ & $46(29.11 \%)$ & \\
\hline & Employee & $75(47.47 \%)$ & $86(54.43 \%)$ & \\
\hline \multicolumn{2}{|c|}{ Total duration of marriage (years) (mean \pm sd) } & $6.0 \pm 3.78$ & $6.1 \pm 4.76$ & 0.686 \\
\hline \multirow[t]{3}{*}{ Socioeconomic status N (\%) } & Low & $64(40.51 \%)$ & $59(37.34 \%)$ & \multirow[t]{3}{*}{0.726} \\
\hline & Moderate & $55(34.81 \%)$ & $54(34.18 \%)$ & \\
\hline & High & $39(24.68 \%)$ & $45(28.48 \%)$ & \\
\hline \multirow[t]{2}{*}{ Residence N (\%) } & Rural & $60(37.97 \%)$ & $54(34.18 \%)$ & \multirow[t]{2}{*}{0.482} \\
\hline & Urban & $98(62.03 \%)$ & $104(65.82 \%)$ & \\
\hline \multicolumn{2}{|l|}{ Age difference (mean $\pm s d)$} & $4.18 \pm 3.65$ & $4.58 \pm 3.65$ & 0.582 \\
\hline \multicolumn{2}{|c|}{ Body mass index $(\mathrm{kg} / \mathrm{m} \wedge 2)($ mean $\pm \mathrm{sd})$} & $27.47 \pm 4.06$ & $27.94 \pm 4.63$ & 0.193 \\
\hline \multirow[t]{2}{*}{ Parity } & Nullipara & $36(22.78 \%)$ & $33(20.89 \%)$ & \multirow[t]{2}{*}{0.006} \\
\hline & Multipara & $122(77.22 \%)$ & $125(79.11 \%)$ & \\
\hline \multicolumn{2}{|c|}{ Gestational age (weeks) (mean \pm sd) } & $30.03 \pm 8.02$ & $29.1 \pm 9.2$ & 0.06 \\
\hline
\end{tabular}


Emotional violence was the most common reported pattern among women exposed to IPV 87.9\% (139/158). However, it was not significantly prominent in depressed women ( $P$ value 0.084). Physical and sexual violence were significantly reported among depressed women ( $P$ value 0.022 and 0.001 , respectively) (Table 2 ).

There was a significant difference between women exposed to violence and those who were not exposed to violence in the total depression scores $(13.63 \pm 5.47$ and $10.65 \pm 5.44$, respectively with a $p$ value $<0.001)$. Two out of 158 women exposed to violence committed suicide actually (Table 3 ).

Multiple factors had a significant role in the prediction of IPV individually as age, parity, education, and husbands' age ( $p$ value $0.003,0.021,0.032$, and $<$ 0.001 respectively). Emotional $(p$ value $<0.001)$ and sexual violence (mild and severe with $p$ value of 0.026 and 0.002 respectively) had significant roles as risk factors for depression during pregnancy either individually or when combined with other factors (Table 4).

\section{Discussion}

This was the first study conducted in Egypt to evaluate the association between IPV and depression during pregnancy. A previous study evaluated the effect of enabling resources and childhood adverse events on anxiety associated with IPV among Egyptian women [20]. In addition, a recent one was conducted to evaluate the association between mental disorders (anxiety and/or depression) with domestic violence [21]. Other studies were conducted among non-pregnant women [22, 23].

Both groups were matched in their demographic characters. Close results were reported by previous studies [24-26]. Emotional violence was the most common reported pattern among women exposed to IPV, followed by physical and sexual violence. These results are higher than a previous research in Vietnam [24]. This would be rendered to the larger sample recruited by them. Also, emotional violence was reported as the most common pattern of violence experienced by women in different countries $[25,26]$. Similar results were reported by a systematic review that included studies conducted from 72 countries about IPV during pregnancy [27].

There was a significant difference between women exposed to violence and those who were not exposed to violence in the total depression scores. Two women exposed to violence committed suicide actually, while suicide ideation was present in about one third of women. Only two studies from Zimbabwe and Pakistan reported on the association between IPV and suicidal ideations or attempts. They concluded that women exposed to violence were at risk of suicidal ideation 5 times than those not exposed to violence [28, 29], while the current study revealed no significant difference in suicide ideation among both groups.

Emotional and sexual violence had significant roles as risk factors for depression during pregnancy. In a study performed among Brazilian women, emotional or physical abuse increased the odds ratio of current major depressive disorder significantly [11]. This agreed with the current study. Recent studies reported that psychological abuse was significantly associated with antenatal depression [30, 31], however; one study reported violence among low income women which limits the validity of their results [31].

Another study reported that physical violence was a powerful determinant for postpartum depression, followed by sexual and emotional violence with no data available about depression during pregnancy [24]. Multiple studies confirmed the association between IPV and postpartum depression [32-34]. This was explained by the relationship between violent behavior and poor mental health [35, 36]. Another study demonstrated that emotional abuse has a damaging effect as physical abuse [37]. This would be explained by the presence of common features between violence and depression such as humiliation and entrapment. Also, depression in women develops

Table 2 Distribution of different types of violence (emotional, physical, sexual) among study groups

\begin{tabular}{lllll}
\hline & & Not Depressed (156) & Depressed (160) & $P$ value \\
\hline Emotional N (\%) & No & $95(60.9 \%)$ & $82(51.25 \%)$ & $0.084^{\mathrm{a}}$ \\
& Yes & $61(39.1 \%)$ & $78(48.75 \%)$ & $115(71.88 \%)$ \\
Physical N (\%) & No & $129(82.69 \%)$ & $45(28.13 \%)$ & $0.022^{\mathrm{a}}$ \\
& Yes & $27(17.31 \%)$ & $145(90.63 \%)$ & $<0.001^{\mathrm{a}}$ \\
Sexual N (\%) & No & $154(98.72 \%)$ & $15(9.38 \%)$ & \\
& Yes & $2(1.28 \%)$ & \\
\hline
\end{tabular}

Depression was considered in women with a score $\geq 14$. Emotional, physical, and sexual abuses were defined by an affirmative answer to one or several of the three or four questions about each kind of violence in NORAQ

${ }^{\text {a }}$ Chi- square test 
Table 3 Associations between violence and different variables regarding depression among both study groups

\begin{tabular}{llll}
\hline & No IPV (158) & IPV (158) & P value \\
\hline $\begin{array}{lll}\text { Depression score (mean } \pm \text { sd) } \\
\text { Trial of suicide N (\%) }\end{array}$ & $10.65 \pm 5.44$ & $13.63 \pm 5.47$ & $<0.001^{\text {a }}$ \\
$\begin{array}{l}\text { Depression not likely } \\
\text { Score }<8^{*}\end{array}$ & $0(0 \%)$ & $2(1.27 \%)$ & $0.156^{\mathrm{b}}$ \\
$\begin{array}{l}\text { Depression possible } \\
\text { Score } 9-11^{*}\end{array}$ & $22(38.6 \%)$ & $32(15.8 \%)$ & $<0.0001^{c}$ \\
$\begin{array}{l}\text { Fairly high possibility of depression } \\
\text { Score } 12-13^{*}\end{array}$ & $26(16.5 \%)$ & $19(12 \%)$ & $0.174^{c}$ \\
$\begin{array}{l}\text { Probable depression } \\
\text { Score } \geq 14^{*} \\
\text { Positive score on question } 10 \text { (suicidal risk) }\end{array}$ & $49(31 \%)$ & $82(51.9 \%)$ & $0.297^{c}$ \\
\hline
\end{tabular}

* EPDS parameters were used to characterize depression

a Mann- Whitney U test

${ }^{b}$ Fisher's- Exact test

c chi- square test

as a result of sense of loss which may be provoked by violence [21].

\section{Strength and limitations of the study}

We addressed a very sensitive issue that could be underestimated as women might be ashamed to disclose their actual experiences. We recruited a control group who were not exposed to violence. The study was conducted as a cross sectional study, which cannot determine a causal relationship. This was a hospital based study which limits the generalizability of the results. We did not evaluate the recruited women for evidence of postpartum depression.

\section{Research implications}

Conducting community based studies would be recommended. Evaluating the effect of IPV on depression during pregnancy with continuing follow up after delivery would be more informative. Also, its impact on perinatal outcome would be evaluated.

\section{Conclusions}

There was a strong association between IPV and depression during pregnancy. Other factors contributed significantly to antepartum depression as husbands' age and education.

Table 4 Single and multiple linear regressions for significant factors related to depression

\begin{tabular}{|c|c|c|c|}
\hline \multirow[t]{2}{*}{ Variables } & \multirow{2}{*}{$\begin{array}{l}\text { Single linear } \\
P \text { value }\end{array}$} & \multicolumn{2}{|c|}{ Multiple linear } \\
\hline & & $P$ value & $\beta(95 \% \mathrm{Cl})$ \\
\hline Age (years) & 0.003 & $<0.001$ & $0.210(0.101-0.32)$ \\
\hline Husband's age (years) & $<0.001$ & - & - \\
\hline Husband's Education & 0.032 & 0.005 & $1.072(0.318-1.825)$ \\
\hline Psychological violence- mild & 0.001 & - & - \\
\hline Psychological violence- moderate & $<0.001$ & - & - \\
\hline Psychological violence- severe & $<0.001$ & $<0.001$ & $4.799(2.347-7.251)$ \\
\hline Physical violence- mild & $<0.001$ & - & - \\
\hline Physical violence- moderate & $<0.001$ & - & - \\
\hline Physical violence- severe & 0.014 & - & - \\
\hline Sexual violence- mild, no genital contact & $<0.001$ & 0.026 & $31.246(3.721-58.772)$ \\
\hline Sexual violence- moderate & $<0.001$ & - & - \\
\hline Sexual violence- severe & $<0.001$ & 0.002 & 5.999 (2.168-9.829) \\
\hline Parity & 0.021 & - & - \\
\hline Gestational age (weeks) & $<0.001$ & $<0.001$ & $-0.018(-0.027--0.008)$ \\
\hline Duration of marriage (years) & 0.006 & - & - \\
\hline
\end{tabular}

For the construction of logistic regression models for the prediction of antenatal depression the dependent variable was the presence or absence of depression. This was put against all of the variables that it depended upon; hence, there were multiple simple logistic models each with a significant factor. These significant factors were put in a model and factors were removed one by one to produce a best-fit multiple logistic model 


\section{Abbreviations}

IVP: Intimate partner violence; WHO: World health organization; PPD : Postpartum depression; NORAQ: NorVold Domestic Abuse Questionnaire; EPDS: Edinburgh Postnatal Depression Scale

\section{Acknowledgments}

Not applicable.

\section{Authors' contributions}

WFG: Protocol/project development, Data collection and management, manuscript writing/editing. M E: Data collection and analysis. AAA: Data collection and management, Manuscript writing/editing. HMG: Data collection and management, Data analysis, Manuscript writing/editing. TYMA: Data collection and management, Manuscript writing/editing. All authors have read and approved the manuscript.

\section{Funding}

Self-funded research.

\section{Availability of data and materials}

The datasets used and/or analyzed during the current study available from the corresponding author on reasonable request. All data generated or analyzed during this study are included in this published article.

\section{Declarations}

\section{Ethics approval and consent to participate}

This study was conducted after approval of the research ethics committee of the faculty of medicine, Suez Canal University, in January 2019 with a number of 4012. All procedures performed in the study were following the ethical standards of the institutional and/or national research committee and with the 1964 Helsinki declaration and its later amendments or comparable ethical standards. This article does not contain any studies with animals performed by any of the authors. Informed written consent was obtained from all participants before enrollment in the study.

\section{Consent for publication}

Not applicable.

\section{Competing interests}

None.

Received: 17 July 2020 Accepted: 7 June 2021

Published online: 12 July 2021

\section{References}

1. Gureje O, Stein DJ. Disorders, diagnosis, and classification. In: Patel V, Minas $\mathrm{H}$, Cohen A, Prince MJ, editors. Global mental health: principles and practice. United States of America: Oxford University Press; 2014. p. 27-40.

2. Gavin NI, et al. Perinatal depression: a systematic review of prevalence and incidence. Obstet Gynecol. 2005;106(5, Part 1):1071-83.

3. Klainin P, Arthur DG. Postpartum depression in Asian cultures: A literature review. Int J Nurs Stud. 2009;46(10):1355-73. https://doi.org/10.1016/j. ijnurstu.2009.02.012.

4. Desmarais SL, Pritchard A, Lowder EM, Janssen PA. Intimate partner abuse before and during pregnancy as risk factors for postpartum mental health prob-lems. BMC Pregnancy Childbirth. 2014;14(1):132. https://doi.org/10.11 86/1471-2393-14-132.

5. Garcia-Moreno C, et al. Global and regional estimates of violence against women: prevalence and health effects of intimate partner violence and non-partner sexual violence. Geneva: World Health Organization; 2013.

6. Garcia-Moreno C, Jansen HA, Ellsberg M, Heise L, Watts CH. Prevalence of intimate partner violence: findings from the WHO multi-country study on women's health and domestic violence. Lancet. 2006;368(9543):1260-9. https://doi.org/10.1016/S0140-6736(06)69523-8.

7. Berhanie E, Gebregziabher D, Berihu H, Gerezgiher A, Kidane G. Intimate partner violence during pregnancy and adverse birth outcomes: a casecontrol study. Reprod Health. 2019;16(1):22. https://doi.org/10.1186/s12978019-0670-4.

8. Mezey GC, Bewley S. Domestic violence and pregnancy. Br J Obstet Gynaecol. 1997;104(5):528-31. https://doi.org/10.1111/j.1471-0528.1997.tb11526.x.
9. White ME, Satyen L. Cross-cultural differences in intimate partner violence and depression: a systematic review. Aggress Violent Behav. 2015;24:120-30. https://doi.org/10.1016/j.avb.2015.05.005.

10. Bennett HA, Einarson A, Koren G, Einarson TR. Prevalence of depression during pregnancy: systematic review. Obstet Gynecol. 2004;103(4):698-709. https://doi.org/10.1097/01.AOG.0000116689.75396.5f.

11. Pereira PK, Lovisi GM, Pilowsky DL, Lima LA, Legay LF. Depression during pregnancy: prevalence and risk factors among women attending a public health clinic in Rio de Janeiro, Brazil. Cad Saúde Pública, Rio de Janeiro. 2009;25(12):2725-36.

12. Heron J, O'Connor TG, Evans J, Golding J, Glover V, Study Team ALSPAC. The course of anxiety and depression through pregnancy and the postpartum in a community sample. J Affect Disord. 2004;80(1):65-73. https://doi.org/10.1016/j.jad.2003.08.004.

13. Fisher J, Tran TD, Biggs B, Dang TH, Nguyen TT, Tran T. Intimate partner violence and perinatal common mental disorders among women in rural Vietnam. Int Health. 2013;5(1):29-37. https://doi.org/10.1093/inthealth/ ihs012.

14. Ibrahim ZM, Sayed Ahmed WA, El-Hamid SA, Hagras AM. Intimate partne violence among Egyptian pregnant women: incidence, risk factors, and adverse maternal and fetal outcomes. Clin Exp Obstet Gynecol. 2015:2. https://doi.org/10.12891/ceog1829.2015.

15. Yount K, Li L. Domestic violence and obesity in Egyptian women. J Biosoc Sci. 2011;43(1):85-99. https://doi.org/10.1017/S0021932010000441.

16. El-Gilany $\mathrm{A}-\mathrm{H}$, El-Wehady $\mathrm{A}$, El-Wasify $\mathrm{M}$. Updating and validation of the socioeconomic status scale for health research in Egypt. East Mediterr Health J. 2012;18(9):962-8. https://doi.org/10.26719/2012.18.9.962.

17. Haddad LG, Shotar A, Younger JB, Alzyoud S, Bouhaidar CM. Screening for domestic violence in Jordan: validation of an Arabic version of a domestic violence against women questionnaire. Int J Womens Health. 2011;3:79-86.

18. Cox JL, Holden JM, Sagovsky R. Detection of postnatal depression: development of the 10-item Edinburgh postnatal depression scale. $\mathrm{Br} \mathrm{J}$ Psychiatry. 1987;150(6):782-6. https://doi.org/10.1192/bjp.150.6.782.

19. BC Reproductive Mental Health Program and Perinatal Services BC. (2014), Best Practice Guidelines for Mental Health Disorders in the Perinatal Period. Available at: http://tiny.cc/MHGuidelines.

20. Shaikh AK, Pearce B, Yount KM. Effect of enabling resources and risk factors on the relationship between intimate partner violence and anxiety in evermarried women in Minya, Egypt. Fam Viol. 2017;32(1):13-23. https://doi. org/10.1007/s10896-016-9848-5.

21. Abdelhai R, Mosleh $H$. Screening for antepartum anxiety and depression and their association with domestic violence among Egyptian pregnant Women. J Egypt Public Health Assoc. 2015;90:101-8 Egyptian Public Health Association 0013-2446.

22. Vizcarra B, Hassan F, Hunter WM, Munoz SR, Ramiro L, De Paula CS. Partner violence as a risk factor for mental health among women from communities in Philippines, Egypt, Chile, and India. Inj Control Saf Promot. 2004;11(2):125-9. https://doi.org/10.1080/15660970412331292351.

23. Habib SR, Abdel Azim EK, Fawzy IA, Kamal NN, El Sherbini AM. Prevalence and effects of violence against women in a rural community in Minia governorate, Egypt. J Forensic Sci. 2011;56(6):1521-7. https://doi.org/1 0.1111/j.1556-4029.2011.01886.x.

24. Nhi TT, Hanh NTT, Hinh ND, Toan NV, Gammeltoft $T$, Rasch V, et al. Intimate Partner Violence among Pregnant Women and Postpartum Depression in Vietnam: A Longitudinal Study. Biomed Res Int. 2019;4717485:9. https://doi. org/10.1155/2019/4717485

25. Jackson CL, Ciciolla L, Crnic KA, Luecken LJA, Gonzales NAA, Coonrod DVA. Intimate partner violence before and during pregnancy: related demographic and psychosocial factors and postpartum depressive symptoms among mexican american women. J Interpersonal Viol. 2015; 30(4):659-79. https://doi.org/10.1177/0886260514535262.

26. Groves AK, Kagee A, Maman S, Moodley D, Rouse P. Associations between intimate partner violence and emotional distress among pregnant women in Durban, South Africa. J Interpersonal Viol. 2012;27(7):1341-56. https://doi. org/10.1177/0886260511425247.

27. Lafaurie MMV. Violencia de la pareja 'intima contra las mujeres en el embarazo: una lectura cr'itica con perspectiva de g'enero. Revista Colombiana de Enfermer'ı. 2015;10(10):64-77. https://doi.org/10.18270/rce. v10i10.581.

28. Miura A, Fujiwara T. Intimate partner violence during pregnancy and postpartum depression in Japan: A cross sectional study. Front Public 
Health. 5:81. published: 24 April 2017. https://doi.org/10.3389/fpubh.2017. 00081.

29. Asad N, Karmaliani R, Sullaiman N, Bann CM, Mc Clure EM, Pasha O, et al. Prevalence of suicidal thoughts and attempts among pregnant Pakistani women. Acta Obstet Gynecol Scand. 2010;89(12):1545-51. https://doi.org/1 0.3109/00016349.2010.526185.

30. Shamu S, Zarowsky C, Roelens K, Temmerman M, Abrahams N. High frequency intimate partner violence during pregnancy, postnatal depression and suicidal tendencies in Harare, Zimbabwe. Gen Hosp Psychiatry. 2016;38: 109-14. https://doi.org/10.1016/j.genhosppsych.2015.10.005.

31. Kastello JC, Jacobsen KH, Gaffney KF, Kodadek MP, Sharps PW, Bullock LC. Predictors of depression symptoms among low-income women exposed to perinatal intimate partner violence (IPV). Community Ment Health J. 2016; 52(6):683-90. https://doi.org/10.1007/s10597-015-9977-y.

32. Yu H, Jiang X, Bao W, Xu G, Yang R, Shen M. Association of intimate partner violence during pregnancy, prenatal depression, and adverse birth outcomes in Wuhan, China. BMC Pregnancy and Childbirth. 2018;18(1):469. https://doi.org/10.1186/s12884-018-2113-6.

33. Ludermir AB, Lewis G, Valongueiro SA, De Araujo TVB, Araya R. Violence against women by their intimate partner during pregnancy and postnatal depression: a prospective cohort study. Lancet. 2010;376(9744):903-10. https://doi.org/10.1016/S0140-6736(10)60887-2

34. Bonomi AE, Anderson ML, Reid RJ, Rivara FP, Carrell D, Thompson RS. Medical and psychosocial diagnoses in women with a history of intimate partner violence. JAMA Intern Med. 2009;169(18):1692-7.

35. Varma D, Chandra PS, Thomas T, Carey MP. Intimate partner violence and sexual coercion among pregnant women in India: Relationshipwith depression and post-traumatic stress disorder. J Affect Disord. 2007;102(1-3): 227-35

36. Yount KM, Dijkerman S, Zureick-Brown S, VanderEnde KE. Women's empowerment and generalized anxiety in Minya, Egypt. Soc Sci Med. 2014; 106:185-93. https://doi.org/10.1016/j.socscimed.2014.01.022.

37. Marshall LL. Development of the severity of violence against women scales. J Fam Violence. 1992;7(2):103-21. https://doi.org/10.1007/BF00979027.

\section{Publisher's Note}

Springer Nature remains neutral with regard to jurisdictional claims in published maps and institutional affiliations.

Ready to submit your research? Choose BMC and benefit from:

- fast, convenient online submission

- thorough peer review by experienced researchers in your field

- rapid publication on acceptance

- support for research data, including large and complex data types

- gold Open Access which fosters wider collaboration and increased citations

- maximum visibility for your research: over $100 \mathrm{M}$ website views per year

At $\mathrm{BMC}$, research is always in progress.

Learn more biomedcentral.com/submissions 